\title{
Linguistic Landscape in Educational Spaces
}

\author{
Sheryl Bernardo-Hinesley* \\ Western Washington University \\ *bernars3@wwu.edu \\ Received : 2020-09-18 \\ Accepted : 2020-11-17 \\ DOI: $10.46303 /$ jcve.2020.10
}

\begin{abstract}
How to cite this paper: Bernardo-Hinesley, S. (2020). Linguistic Landscape in Educational Spaces, Journal of Culture and Values in Education, 3(2), 13-23. doi.org/10.46303/jcve.2020.10

This is an Open Access article distributed under the terms of the Creative Commons Attribution 4.0 International license (https://creativecommons.org/licenses/by/4.0/)
\end{abstract}

\section{Abstract}

Educational institutions, whether privately owned or state funded, are a meeting place for students coming from diverse linguistic and cultural backgrounds. Educational institutions as learning environments and spaces not only play a fundamental role in the development of an individual, but also perpetuate various ideologies related to languages, politics, cultures, and society among others. In relation to language ideology, linguistic landscape is a novel field which allows sociolinguists to analyze how spaces are constituted through the language(s) employed in public signage as signs enable a dynamic process in which the language(s) used in these signs and those who pass by said signs influence each other to shape the landscape of their community. It enables the identification of the relative power and vitality of the language(s) in a particular community that may or may not appear in public signage. Language(s) displayed in public spaces can also be interpreted as a reflection of the ideological conflicts within a community. Respectively, there is a growing interest towards the study of the linguistic landscape in educational spaces, also known as schoolscape. School, a central civic institution, represents a deliberate and planned environment where learners are subjected to powerful messages about language(s) from local and national authorities. Accordingly, by reviewing past studies, this paper proposes to initiate discussion and investigation of the practices and the language(s) utilized in signs within educational spaces in the United States as institutions can perpetuate language ideologies, which can either foster or hinder bilingual education.

Keywords: linguistic landscape, schoolscape, language ideology, educational spaces bilingual education 


\section{Introduction}

The aim of this paper is threefold. First, it provides an introduction to the concept of linguistic landscape as initially introduced by Landry \& Bourhis (1997) and expanded by Stroud \& Mpendukana (2009). Second, the concept will be discussed in relation to language education in spaces of public educational institutions by reviewing the findings of past schoolscape studies (Astillero, 2017; Biró, 2016; Bisai \& Singh, 2018; Brown, 2012; Chirimala, 2017; Gorter \& Cenoz, 2015; Jakonen, 2018; Szabó, 2015). Third, the development of support as well as suggestions for research towards bilingual education and the current state of world language education in the United States will be encapsulated. A discussion and conclusion will then follow putting forward a proposal to initiate the discussion and investigation of the practices and the language(s) used on signs in educational spaces in the United States.

\section{Linguistic Landscape}

Linguistic landscape is a novel field that has gained prominence in the last two decades. According to the seminal work by Landry \& Bourhis (1997), the notion is defined as "...the language of public road signs, advertising billboards, street names, place names, commercial shop signs, and public signs on government buildings combines to form the linguistic landscape of a given territory, region, or urban agglomeration" (p. 25). These researchers further indicate that signs serve two basic functions: an informational function and a symbolic function. With regards to the function providing information, it imparts an areal marker of a language community's territory and can illustrate clear demarcation of the language boundary of the community with respect to adjacent language groups.

Consequently, the frequency of usage of the group's language on public signage in the territory conveys that service can be solicited and received by means of that language within the territory. With regards to the symbolic function, in a bilingual or multilingual context, the prevalent employment of a language in commercial and governmental signs illustrates a language's status and value in relation to the other language(s) within the setting. In addition, it may articulate its vitality which expresses its strength or weakness in relation to the competing language groups.

In other words, linguistic landscape as a field allows sociolinguists to analyze how spaces are constituted through the language(s) employed in public signage. It is important to note that the initial description by Landry \& Bourhis (1997) does not take into account the complexities encapsulated by late modern, multilingual societies. Accordingly, Stroud \& Mpendukana (2009) draw attention to the notion of social transformation which is a dynamic process that transpires within these societies. The placement of signs, and people's performance and interaction towards said signs within a bilingual or multilingual space must be taken into consideration in linguistic landscape studies since such interactions call to attention the complex reality of the language(s) displayed in common spaces. That is to say that signs enable a lively process wherein language(s) employed in signage and people interact and influence each other to shape the landscape of their community.

Thus, linguistic landscape enables the identification of the relative vitality and power of the language(s) in a particular community that may or may not appear in signs situated in the public space (Cenoz \& Gorter, 2006). The absence or presence of a language in a public space conveys its marginality versus its centrality in the community (Shohamy, 2006a). In addition, languages displayed in public spaces can be interpreted as a reflection of the 
ideological conflicts within a community (Lado, 2011). That is, how languages are used in a determined space is defined by how the said space is configured in the minds of its people which entails the types of interactions and identities possible in such spaces.

\section{Objective}

Numerous researchers have carried out linguistic landscape studies focused in public spaces (Hélot et al., 2012; Marten et al., 2012; Shohamy et al., 2010; Shohamy \& Gorter, 2009). In the recent decade, an emerging interest towards the investigation of the linguistic landscape in educational spaces, also known as schoolscape, is evident (Astillero, 2017; Biró, 2016; Bisai \& Singh, 2018; Brown, 2012; Chirimala, 2017; Gorter \& Cenoz, 2015; Jakonen, 2018; Szabó, 2015). Accordingly, by reviewing the findings of past studies concerning schoolscapes in the following section, a proposal to initiate the examination of the language(s) used on signs in educational spaces is put forward in the discussion and conclusion section. Given that educational institutions can perpetuate language ideologies which can either foster or hinder bilingual education, attention is alluded towards schools in public school districts that provide world language instruction in the United States.

\section{Literature Review}

Educational institutions, whether privately owned or state funded, are a meeting place for learners of diverse linguistic and cultural backgrounds. Specifically, students come from dissimilar familial or circumstantial experiences which condition their language and cultural practices. Correspondingly, educational institutions as learning environment spaces not only play a fundamental role in the development of a learner, but also perpetuate various ideologies related to politics, cultures, society, and languages among others (Kalekin-Fishman, 2004). Relating directly to the matter at hand, a growing interest is evident towards the study of the linguistic landscape in educational spaces, also known as schoolscape. The schoolscape studies discussed in this section (Astillero, 2017; Biró, 2016; Bisai \& Singh, 2018; Brown, 2012; Chirimala, 2017; Gorter \& Cenoz, 2015; Jakonen, 2018; Szabó, 2015) have contributed to the advancement of the methods of analysis in understanding schoolscapes.

The ecology of languages in educational spaces was first introduced in a study conducted by Brown (2012). Brown (2012) states that "...school, a central civic institution, represents a deliberate and planned environment where learners are subjected to powerful messages about language(s) from local and national authorities" (p. 281). In the study, the researcher analyzed the reintroduction of Võro, which is a regional language in southeastern Estonia, in kindergarten and elementary schools. The factors identified as impacting the use of Võro include administrative, community, and parental support, teacher autonomy in language choices, and the physical school space. In the past, regional languages were absent in formal education in schools in Estonia. However, at present, schools provide a setting in which the revitalization of the minority language can take place as speakers sought to halt the decline of the language. Signs in the kindergarten and elementary school classrooms, corridors, foyer, entrance, school museum, and the curriculum were analyzed, as well as the explanations of the teachers and administrators involved in the process of rewriting the signs. The findings of the study stated that the regional language is observed as a historical artifact which enrich the national culture. The author concluded that the reintroduction of the minority language has led to a negotiation in public school spaces. 
In the Basque Autonomous Community in northern Spain, Gorter and Cenoz (2015) analyzed the signs in seven schools according to their function, language distribution, and sign authorship. A policy by the regional government was developed to promote the Basque language. The effort began in the late 1970s when Spanish was the dominant language in the school system. From the analysis of the photographs of the signs taken inside and outside of the classrooms visited, the authors found that signs are employed in different ways for varying functions with distinct objectives in mind. The functions identified are language- or content-related instruction, linguistic and intercultural awareness development, classroom behavioral guidelines, general school guidance, and commercial information display. The study then concluded that multilingual signs contribute to multilingual student literacy and intercultural competence.

In a study carried out by Szabó (2015), the author analyzed and compared the signs found in four state and private schools with alternative curriculum in Budapest, Hungary along with the metadiscourses of the teachers regarding the linguistic landscape of their respective schools. In the analysis of the photographed signs and recorded speech of the teachers, attention towards agency is placed since it reflects an individual's involvement in social activities, which is a tool for portraying community engagement. It is noteworthy that although communism fell in 1989, which facilitated changes in organization of the educational system of the country, teacher-centered ideologies and practices are virtually intact. The author concluded that nationalist ideologies and identities are reconstructed in state schools through signs written by authority or top-down homogenization. On the other hand, private schools illustrated the agency of the students by promoting their unique individuality and creativity through transgressive bottom-up signs. Such practice exemplifies the negotiation of communicative practices. By the same token, based on photographed signs and teacher interviews, the study by Biró (2016) qualitatively analyzed the language learning and instructional ideologies reflected on the signs and the comments made by educators in four primary and four secondary Hungarian schools in Sfântu Gheorghe, Romania. Concealed curricular details are investigated in relation to the instruction of English, German, or Romanian as second languages in Hungarian-medium schools with respect to the functions of the signs, the makers of the signs, their placement, the intended audience, and the duration with which the signs are displayed. Though the first language of the majority is Romanian in this setting, it is not taught as a second language to Hungarian minority students. The author found that the top-down signs evidently portrayed support towards the Romanian language. In addition, the prominence of student work in Romanian and English exemplified the hidden curriculum of the educators which they substantiated with the national curriculum.

Chirimala (2018) investigated how students use schoolscape as they manifest their English language abilities in the contexts of schools ran by the state of Andhra Pradesh, India wherein the state regional language is Telugu. From the recorded sign-centered collaborative multilingual talk by 18 pairs of students in a public secondary institution, the researcher found that signs were able to induce incidental learning. This finding illustrates that signs have pedagogical relevance in language learning. In the dyad conversations, students made reference to the signs within their school when searching for words, planning and organizing textual content, and making crosslinguistic comparisons. The study concluded that students noticed the signs surrounding their school, which were then used as a pragmatic resource for language-related task performance. Likewise, the study by Jakonen (2018) explored how 
students attended to visual and textual materials in the classroom during instructional interactions in a bilingual secondary classroom in Finland. That is, through video-recorded interactions of 14 students in content and language integrated history lessons taught in English, a foreign language in this context, the author analyzed how visual-material resources are used, engaged, and modified for the purpose of conducting instruction. It is noteworthy that the instructor commonly uses both Finnish and English in her lessons. The author concluded that the management and orientation of classroom texts and other material artifacts point towards negotiations as not only a matter of talk, but also constructed through signs and other semiotic resources such as gaze, gesture, and pointing.

In the Philippines, as the language policy in education moves towards implementing the use of regional languages as the medium of instruction, Astillero (2017) investigated the linguistic landscape of a public secondary school in Irosin, Sorsogon, Philippines wherein regional Bikol languages are spoken. In particular, it identified the languages employed in the signs, its authors, and the regulation of signs within this school space. Photographs inside and outside of the classrooms were taken and analyzed according to the displayed languages on the signs, the maker of the signs, the functions of the signs, their intended audience or readers, and the materials used to produce the signs. In this setting, it is remarkable that English only signs on durable materials, which ensure lasting presence, were primarily topdown and highly visible. The author concluded that though bilingual and mixed (Bikol, Filipino, and English) languages are employed in some of the signs analyzed in the study, the practice illustrated the lack of support towards the multilingual speakers in the area in formal educational spaces. Thus, this absence of support manifests the uncooperativeness of the school concerning multilingualism as a language policy promoted by the Department of Education of the Philippines. Similarly, the signs analyzed from five schools in Jhargram and Paschim Medinipur Districts, West Bengal, India by Bisai \& Singh (2018) indicated that the negligible use of Santali, a regional language, had a negative effect on Santali students given that the dominant medium of instruction is Bengali. Similarly, in this study, photographs of signs were collected from public and private areas of the five primary multilingual schools. Apart from analyzing the frequency of visibility of the minority language in the school, teacher and student informal interviews were conducted to ascertain their attitudes towards the minority languages within the region. As the signs were often monolingual illustrating Bengali as the dominant language given its official status in the state, it exemplified that minority languages are scarcely given space in these multilingual schools. This then showed the attitude towards the minority languages and cultures in the district. In addition, the top-down signs portrayed the little participation of students and the community in these schools.

In the subsequent section, language instruction, bearing in mind the support towards bilingual education and the state of world language education, in the United States will be discussed in a concise manner.

\section{Bilingual and World Language Education in the United States}

According to the 2009-2013 American Community Survey, 380 languages or language groups are reported to be spoken in the United States. This clearly shows that numerous languages are spoken by 61.7 million or approximately $20 \%$ of the United States population. Explicitly, one-fifth of the country are from linguistically diverse backgrounds and that they speak a language other than English at home. Though a federal regulation regarding the use 
of English and other languages does not exist, English is the official language de facto and has been declared as an official language in 28 state legislations (García, 2011). Provided that educational institutions play an important role in the (re)production and challenging of ideologies, the languages that are used (or not used) in schools and school districts convey meaning related to politics, culture, and the society in general. That said, this section presents an insight regarding the ways in which English is fostered in educational institutions through bilingual education.

Through the Lau Remedies, bilingual education in the United States was first introduced in California in 1974 in view of the ruling of the country's Supreme Court towards the provision of assistance to students of diverse language backgrounds (StewnerManzanares, 1988). The objective of this Federal Bilingual Education Act was to safeguard students from lagging behind in the educational system due to limited or lack of English language speaking ability. In order to do so, bilingual education program was defined as one that offered instruction in English and in the language of the student, so that they may advance effectively in academic school systems. The goal was to prepare such students to participate expeditiously in regular classrooms wherein English is the language of instruction through the establishment of regional support centers with consultants that provide guidance and support to schools and the allocation of funds for research grants and expansion of bilingual programs and curricula.

Consequently, in the 1978 amendment of the Federal Bilingual Education Act, the definition of eligible students was broadened not only to refer to those who have limited speaking ability in English, but to those students with difficulty understanding, reading, writing, or speaking English (Castellanos, 1983). That is to say that reading and writing were added as part of the program goals. In addition, bilingual education programs were stipulated to be transitional, and that the language of the student was only to be utilized to the point necessary to facilitate the student's proficiency in English. It is important to note that programs with objectives to maintain the first language of the student were not funded.

Accordingly, the Federal Bilingual Act of 1984 addressed the need for flexibility in the implementation of bilingual education programs by according the local school districts the ability to decide how their students with limited English proficiency should be taught (Stewner-Manzanares, 1988). This approach enabled the school districts to apply for funding for programs which employed diverse strategies in teaching depending upon their needs. Grants were awarded to different types of bilingual education programs which include transitional, special alternative, and developmental. In a transitional bilingual education program, up to $40 \%$ may be students that are not of limited proficiency in English. In such a program, the instruction of English is coupled with the first language of the student. It is important to note that $75 \%$ of the federal funding dedicated to supporting bilingual instructional programs was reserved towards this type of program. In a special alternative bilingual education program, the first language of the students is not used in instruction. To be precise, English is employed in instruction along with instructional support services to aid in the development of English proficiency. In the provision of 1988, 25\% of the federal funding was authorized to be allocated to special alternative bilingual programs. Lastly, in a developmental bilingual program which is also known as two-way bilingual, two-way immersion, and dual language immersion, students are provided with instruction in English and the first language. As the objective of such program is to achieve proficiency in both of 
these languages, the classroom includes a balance of students whose first language is English and those whose first language is a language other than English. That is to say that students receive instruction in English and the partner language. It is important to note that there are two dual language immersion model configurations (Palmer et al., 2014). The description provided above makes reference to two-way dual language model. In a one-way dual language immersion model, students in a classroom share a common first language which is used as the medium of instruction.

Anderson and Boyer (1970) posit the definition of bilingual education as the "....instruction in two languages and the use of those two languages as mediums of instruction for any part or, or all, of the school curriculum" (p. 12). This definition immediately excludes bilingual education programs in which students are only instructed in the language that is being facilitated to be acquired. That is to say that the key characteristic for a program to be bilingual is that two languages are used as mediums of instruction. Notwithstanding, it is striking that bilingual education programs supported by the Federal Bilingual Education Acts of the United States explicitly promote the language development in English rather than foster bilingualism. Clearly, the emphasis in the employment of English as the language of instruction can be observed in the way the federal government of the United States stipulated bilingual education programs.

On the other hand, according to the American Councils for International Education (2017), the interest in learning a second language other than English by native and non-native speakers is rising in many school districts in the United States. The American Councils for International Education is a nonprofit organization that partners with institutions and governments to advance language training, cultural exchange, and educational development. Of the country's population, 54 million are school-age, ages of 5 to 17 years old. Enrollment in world language courses other than English at the K-12 setting account for approximately $20 \%$ of the total school-age population as reported by the states which is approximately 10.6 million students. Although a number of states are involved in efforts towards offering K-12 world language education, decisions concerning the elimination or consolidation of language programs are being taken at the local levels which sets hurdles in the analysis of the efforts being done.

Moreover, the survey exemplified that Spanish is the world language with the highest enrollment in the country with approximately 7.4 million students (American Councils for International Education, 2017). The world languages that follow this enrollment are French, German, Chinese, American Sign Language, Japanese, Arabic, Latin, and Russian, respectively in decreasing order. It is noteworthy that in K-12 settings, secondary school systems commonly have language programs. As illustrated in the survey, Spanish is the language with the highest number of high school programs with 8,177 programs or $46 \%$ of all secondary world language programs in the United States. French follows Spanish at $21 \%$, followed by German at 8.7\%, Latin at 8.5\%, Chinese at 6.4\%, American Sign Language at 3.5\%, Japanese at $2.4 \%$, Arabic at $0.9 \%$, and Russian at $0.8 \%$. Apart from the instruction of major world languages other than English, about 19\% of the high schools in the country offer Less Commonly Taught Languages courses.

Bearing in mind the support towards bilingual education and the current state of world language education in the United States, it will be insightful to examine signs inside language classrooms, and inside and outside of schools, to bring to light the practices and 
ideologies within these schools as they relate to proficiency development in a language other than English.

\section{Discussion and Conclusion}

It is apparent that English is a widely spoken language in the United States. Despite its predominance and officialization in many states, it is evident that many people in the country speak a language other than English (American Councils for International Education, 2017). The majority of those who indicated that they speak a language other than English state that they acquired it at home. This may then allude to challenges encountered by these individuals in developing their language proficiency in the home language in educational institutions that offer language instruction.

In the United States, over 11.7 million school-aged children speak a language other than English at home. As discussed in the previous section, bilingual education programs in the United States are primarily designed to transition said students towards English proficiency rather than to maintain and develop their proficiency in both English and the home language. As local school districts have the ability to decide how their students with limited English proficiency be taught depending upon their needs, it is of relevance to examine the language(s) employed on the signs within public educational institutions that offer language instruction in a language other than English in the country. The 'tourist guide technique' employed by Szabó (2015) and Biró (2016) will bring to light possible hidden and implicit policies and ideologies of a school and its educators. In this methodology, an educator who serves as a guide through the school is interviewed by the researcher during the process of taking photographs of the signs. Language choice and the reasons for displaying particular signs are some of the possible interview questions in this approach. Taking into consideration the findings of the two studies, it may be possible that nationalist ideologies and identities are being supported and reconstructed within a particular school which may capture possible ideological conflict in a community of diverse language backgrounds.

The inscribed language(s) on the signs in the hallways and building façades of an educational institution can function as tools for orientation towards a particular language ideology. Such material configuration may then motivate or discourage interest in developing proficiency in a language spoken at home. In order to support these school-aged children of linguistically diverse backgrounds, inclusive space must be fostered within these schools. As stated by Brown (2012), schoolscape represent the material environment where signs "constitute, reproduce, and transform language ideologies" (p. 282). That is to say that signs in schools and students who speak a language other than English at home reciprocally interact and influence each other continually shaping and reflecting the landscape of their community. By analyzing not only the language(s) used on the signs within a school, but also the makers of the signs, materials used to produce the signs, functions of the signs, and intended audience of the signs as in Astillero (2017), Bisai and Singh (2018), and Gorter and Cenoz (2015), the support towards home language proficiency development can be identified. The analysis of the makers of the signs will illustrate if students only or students, their parents, and the community are involved in the making of the signs or if the signs are only put forward by school authorities. In addition, it may illustrate the engagement and involvement of the teachers and the school with their respective community. With regards to the materials used for the production of the signs, this may show the allocation of resources 
and the durability or duration with which the signs are displayed. That is to say that by analyzing these factors, the subsequent questions regarding support towards the languages spoken in every community in the United States will be addressed. How are schools recognizing the language diversity in their communities? How are the different languages taught and the languages spoken at home being reflected in schools? How often are the languages taught utilized on school signs? How are the languages used on school signs distributed? Are there bilingual or mixed language signs? Who are the authors of the signs? Are language educators actively promoting the languages spoken by their students? Do students from linguistically diverse backgrounds have agency in using their home language in schools? Which languages are used for different functions? What are the guidelines in placing signs in the school?

Given the multilingual reality of the country and the world, it is imperative that educational institutions provide space which prepares students for this reality. That said, as schoolscape play a fundamental role in perpetuating ideologies, in particular that of language, it is vital that the signs employed in schools in the United State be examined. As the (re)production of signs may exhibit either shifting or contradictory local and national ideologies towards languages. It is therefore essential to document the signage in educational spaces to ensure that the needs of the local communities, specifically students of diverse language backgrounds, are being addressed. In a school highly attended by students who speak a language other than English at home, if school signs are mainly written in English by school authorities using durable and costly materials, it may portray implied policy and language ideology on part of the educators and school authorities. In contrast, if at the same school students and perhaps community members are engaged in the making of signs reflecting their home language given the involvement of the language educators in their community, students may perceive a sense of support towards the development of their proficiency in the home language in addition to being taught in the school. For future studies, the incorporation of language prominence and framing as additional factors for analysis in schoolscapes may point towards the textual discourse in a school. Furthermore, to understand if students who speak a language other than English feel incited by their classmates whose first language is English, student language attitudes and language challenges must be explored by means of the 'tourist guide technique' with a few students instead of a teacher. Along with the examination of the signs within schools, analyzing student language attitudes may provide a better understanding of the dynamic of languages and language ideologies in the United States schools.

\section{Acknowledgements}

The author would like to thank the two anonymous peer reviewers for their insightful feedback and careful reading of the manuscript. 


\section{References}

American Councils for International Education. (2017, June). The National K-12 Foreign Language Enrollment Survey Report.

https://www.americancouncils.org/sites/default/files/FLE-report-June17.pdf

Andersson, T., \& Boyer, M. (1970). Bilingual Schooling in the United States. National Educational Laboratory Publishers.

Astillero, S. F. (2017). Linguistic schoolscape: Studying the place of English and Philippine languages of Irosin secondary school. Asia Pacific Journal of Education, Arts and Sciences, 4(4), 30-37.

Biro, E. (2016). Learning schoolscapes in a minority setting. Acta Universitatis Sapientiae, Philologica, 8(2), 109-121.

Bisai, S., \& Singh, S. (2018). Schoolscape in minority school: An empirical study in Jhargram and Paschim Medinipur District, India. Proceedings of the International Conference on Education, Teaching and Learning. ICE18 France Conference.

Brown, K. (2005). Estonian schoolscapes and the marginalization of regional identity in education. European Education, 37, 78-89.

Brown, K. (2012). The linguistic landscape of educational spaces: Language revitalization and schools in southeastern Estonia. In H. Marten, D. Gorter, \& L. van Mensel (Eds.), Linguistic landscapes and minority languages, (pp. 281-298). Palgrave.

Castellanos, D. (1983). The best of two worlds: Bilingual-bicultural education in the U.S. New Jersey State Department of Education.

Cenoz, J., \& Gorter, D. (2006). Linguistic Landscape and Minority Languages. International Journal of Multilingualism, 3(1), 67-80.

Cenoz, J., \& Gorter, D. (2008). Linguistic landscape as an additional source of input in second language acquisition. International Review of Applied Linguistics in Language Teaching, 46, 257-276.

Chimirala, U. (2018). Appropriating to the schoolscape: A study of reference of linguistic landscape in dyad text construction. Indian Journal of Applied Linguistics, 44(1-2), 3865.

Dressler, R. (2015). Signgeist: Promoting bilingualism through the linguistic landscape of school signage. International Journal of Multilingualism, 12(1), 128-145.

García, O. (2011). Planning Spanish: Nationalizing, minoritizing and globalizing performances. In M. Díaz-Campos (Ed.), The handbook of Hispanic sociolinguistics, (pp. 667-685). Wiley-Blackwell.

Garcia, S. B., \& Dominguez, L. (1997). Cultural contexts that influence learning and academic performance. In Silver, L. B. (Ed.), Child and Adolescent Psychiatric Clinic of North America: Academic Difficulties, (pp. 621-55). Saunders Co.

Gorter, D., \& Cenoz, J. (2007). Knowledge about language and linguistic landscape. In N. H. Hornberger (Ed.), Encyclopedia of Language and Education, (pp. 1-13). Springer Science.

Gorter, D., \& Cenoz, J. (2015). Linguistic landscapes inside multilingual schools. In B. Spolsky, M. Tannenbaum, \& O. Inbar (Eds.), Challenges for language education and policy: Making space for people, (pp. 151-169). Routledge. 
Hélot, C., Barni, M., Janssens, R., \& Bagna, C. (Eds.). (2012). Linguistic Landscapes, Multilingualism and Social Change. Peter Lang.

Jakonen, T. (2018). The environment of a bilingual classroom as an interactional resource. Linguistics and Education, 44, 20-30.

Kalekin-Fishman, D. (2004). Ideology, Policy, and Practice: Education for Immigrants and Minorities in Israel Today. Kluwer Academic Publishers.

Lado, B. (2011). Linguistic landscape as a reflection of linguistic ideological conflict in the Valencian community. International Journal of Multilingualism, 8(2), 135-150.

Landry, R., \& Bourhis, R. (1997). Linguistic Landscape and ethnolinguistic vitality: An empirical study. Journal of Language and Social Psychology, 16(1), 23-49.

Malinowski, D. (2015). Opening spaces of learning in the linguistic landscape. Linguistic Landscape: An International Journal, 1, 95-113.

Marten, H.F., Van Mensel, L., \& Gorter, D. (2012). Studying Minority Languages in the Linguistic Landscape. In D. Gorter, H. F. Marten \& L. van Mensel (Eds.) Minority Languages in the Linguistic Landscape, (pp. 1-15). Palgrave-MacMillan.

May, S. (2010). Curriculum and the Education of Cultural and Linguistic Minorities. In P. Peterson, E. Baker, \& B. McGaw (Eds.), International Encyclopedia of Education, 1, 293-298. Elsevier.

Palmer, D., Ballinger, S., \& Peter, L. (2014). Classroom interaction in one-way, two-way, and indigenous immersion contexts. Journal of Immersion and Content-Based Language Education, 2(2), 225-240.

Shohamy, E. (2006a). Language policy: Hidden agendas and new perspectives. Routledge.

Shohamy, E. (2006b). Imagined Multilingual Schools: How Come we don't deliver? In O. García, T. Skutnabb-Kangas \& M. Torres-Guzmán (Eds.), Imagining Multilingual Schools (pp. 171-183). Multilingual Matters.

Shohamy, E., Ben-Rafael, E., \& Barni, M. (Eds.). (2010). Linguistic Landscape in the City. Multilingual Matters.

Shohamy, E., \& Gorter, D. (Eds.). (2009). Linguistic Landscape: Expanding the Scenery. Routledge.

Stewner-Manzanares, G. (1988). The Bilingual Education Act: Twenty Years Later. National Clearinghouse for Bilingual Education.

Stroud, C., \& Mpendukana, S. (2009). Towards a material ethnography of linguistic landscape: Multilingualism, mobility and space in a South African township. Journal of Sociolinguistics, 13(3), 363-386.

Szabó, T. P. (2015). The management of diversity in schoolscapes: An analysis of Hungarian practices. Apples - Journal of Applied Language Studies, 9(1), 25-51. 